Article

\title{
Experience of Intimate Partner Violence and Help-Seeking Behaviour among Women in Uganda
}

\author{
Bishwajit Ghose *(1) and Sanni Yaya *(1) \\ School of International Development and Global Studies, Faculty of Social Sciences, University of Ottawa, \\ Ottawa, ON K1N 6N5, Canada \\ * Correspondence: brammaputram@gmail.com (B.G.); sanni.yaya@uottawa.ca (S.Y.)
}

Received: 26 February 2019; Accepted: 5 May 2019; Published: 7 May 2019

\begin{abstract}
Intimate partner violence (IPV) is recognised as a fundamental violation of women's human rights and a widespread phenomenon in Africa. Women's low socioeconomic empowerment, cultural acceptability, and lack of social support exacerbate the health and psychosocial outcomes of IPV among African women. To date, there is no systematic research on IPV and its association with healthcare use among adult women in Uganda. Therefore, we conducted the present study on IPV among Ugandan women of childbearing age (15-49 years). Cross-sectional data on 7536 women were collected from the Uganda Demographic and Health Survey (UDHS-Uganda Demographic and Health Survey 2016). The objectives were to assess the predictors of IPV as well as help-seeking behaviour for victims of IPV. IPV was assessed by women's experience of physical, emotional and sexual violence and healthcare use was assessed by self-reported medical visits during the last 12 months. Logistic regression methods were used to analyse the data. According to descriptive findings, which showed that more than half of the women reported experiencing any IPV $(55.3 \%$, $95 \% \mathrm{CI}=53.6,57.0)$, emotional IPV $(41.2 \%, 95 \% \mathrm{CI}=39.6,42.8)$ was the most prevalent of all three categories, followed by physical $(39.3 \%, 95 \% \mathrm{CI}=37.7,40.9)$ and sexual IPV $(22.0 \%, 95 \% \mathrm{CI}=20.7$, 23.3). In the multivariate analysis, higher age, rural residence, religious background (non-Christian), ethnicity (Banyankore and Itseo), secondary/higher education and husband's alcohol drinking habit were positively associated with women's experience of IPV. Husband's alcohol drinking was found to be a significant barrier to seeking help among those who experienced IPV. In conclusion, our findings suggest a noticeably high prevalence of IPV among Ugandan women. There are important sociodemographic and cultural patterns in the occurrence of IPV that need to be taken into account when designing intervention policies. Special attention should be given to women living with husbands/partners who drink alcohol, as this might increase their odds of experiencing IPV, as well as reduce the likelihood of seeking help.
\end{abstract}

Keywords: intimate partner violence; help seeking; women's health; Uganda

\section{Introduction}

Violence against women (VAW) is a recognised social and public health concern in most sub-Saharan African countries [1-5]. Intimate partner violence (IPV), generally referred to as abusive actions, such as physical, sexual or psychological aggression, as well as coercive acts by a current or former intimate partner, is the most common form of violence against women (VAW) [6-9]. Although IPV can occur within male-to-female and female-to-male as well as same-sex partnerships, the male-to-female type is known to be the most common and is known to women of all ages, cultures, geographies and sexual orientations [10,11]. Lack of quality data makes it hard to quantify the magnitude of the problem, but, given the general acceptance about IPV and lower socioeconocomic empowerment of women, it is assumable that the phenomenon must be widespread. Many governments 
in Africa have so far shown strong policy commitments and are invested in women's education and empowerment projects, but the outcome remains dismal [4,5].

A key reason why investment in women's socioeconomic empowerment does not commensurately reduce the prevalence of VAW, especially IPV, could be the fact that a large proportion of men and women still tend to take some degree of IPV for granted. Indeed, the attitude and perceived norms about the acceptability of the abusive behaviours are necessary preconditions of the continuation of IPV in family settings [12]. A considerable volume of studies has attempted to explain the attitudinal and sociocultural determinants of IPV. The themes that generally emerge from the literature are those surrounding women's empowerment factors and favourable attitude toward IPV. However, not much is known about the situation of IPV, especially in impoverished countries such as Uganda.

Large-scale cross-country studies in Africa reported that a vast majority of the women regard IPV as justifiable in certain circumstances [2,13]. The situation is no different in Uganda, a sub-national study conducted in Rakai reported that both IPV, and attitudes towards condoning it, were widespread [14]. Unfortunately, these issues are not given sufficient weight in public policy-making and in addressing their impact on women's health and socioeconomic mobility-related disparities. There is a convincing amount of evidence suggesting that IPV has a serious aggravating effect on women's reproductive and psychosocial health, self-esteem and financial and overall well-being [15-17]. The impact of IPV can be particularly worrisome in countries with poor institutional infrastructure necessary for providing healthcare and social support for the victims of IPV.

As one of the poorest countries in the continent, Uganda has one of the highest maternal mortality rates (336 deaths per 100,000 live births as of 2018) in Africa and worldwide [18], which depicts the deplorable situation that many women are likely to be undergoing for generations. Reversing the situation is a massive task and would require multisectoral strategies to address the root causes of IPV. Research evidence is necessary to understand the sociocultural origins of the issue and to make effective intervention policies with the broader aim of promoting women's human rights, their quality of social and personal lives and strengthening conjugal relationships. In this study, we aim to address this research gap by analysing population-based cross-sectional data from the Uganda Demographic and Health Survey conducted in 2016. The main objectives are to provide evidence on the prevalence of different types of IPV, help-seeking behaviour for the victims of IPV and their sociodemographic patterns that can be of good use to practitioners involved in women's health and human rights-related programmes.

\section{Methods}

\subsection{Data Source}

Reliable data on topics such as VAW are hard to obtain. We circumvented the scarcity of data by using secondary open-access data from the Uganda Demographic and Health Survey (UDHS 2016) that are available to registered users for research purposes. The UDHS was conducted by Uganda Bureau of Statistics (UBOS) in collaboration with the Ministry of Health (MOH) with technical and financial support provided by the Government of Uganda, the United States Agency for International Development (USAID), the United Nations Children's Fund (UNICEF) and the United Nations Population Fund (UNFPA). The main purpose of these surveys was to provide country-wide data necessary for monitoring and evaluation of population, health and nutrition programmes and assist in evidence-based health policy making. The surveys were conducted by face-to-face interviews on eligible men (15-54 years) and women (15-49 years) using structured questionnaires containing several components: Individual men, women, children (0-59 months), couples and households. The survey took place from 20 June 2016 to 16 December 2016. Year of surveys and scope of sampling areas are listed in Table 1. Data for this study were based on the women's questionnaire. More detailed version of the sampling techniques regarding the surveys was published in the final reports (24-27) [19]. 
Table 1. Sample characteristics. Uganda Demographic and Health Survey (DHS) 2016.

\begin{tabular}{|c|c|c|c|}
\hline Variables & Description & $N=7536$ & $\%$ \\
\hline \multicolumn{4}{|l|}{ Age Group } \\
\hline $15-19$ & \multirow{7}{*}{ Age of the respondent in the interview year. } & 531 & 7.0 \\
\hline $20-24$ & & 1617 & 21.5 \\
\hline $25-29$ & & 1557 & 20.7 \\
\hline $30-34$ & & 1440 & 19.1 \\
\hline $35-39$ & & 1058 & 14.0 \\
\hline $40-44$ & & 766 & 10.2 \\
\hline $45-49$ & & 567 & 7.5 \\
\hline \multicolumn{4}{|l|}{ Residency } \\
\hline Urban & \multirow{2}{*}{ Whether the respondent was a rural or urban resident. } & 1555 & 20.6 \\
\hline Rural & & 5981 & 79.4 \\
\hline Religion & \multirow{4}{*}{ Type of religious affiliation. } & & \\
\hline Christian & & 6565 & 87.1 \\
\hline Other & & 971 & 12.9 \\
\hline \multicolumn{3}{|l|}{ Ethnicity } & \\
\hline Acholi & \multirow{8}{*}{ Ethnic identity of the respondent. } & 429 & 5.7 \\
\hline Baganda & & 908 & 12.0 \\
\hline Bakiga & & 652 & 8.7 \\
\hline Banyankore & & 724 & 9.6 \\
\hline Basoga & & 472 & 6.3 \\
\hline Iteso & & 589 & 7.8 \\
\hline Lango & & 548 & 7.3 \\
\hline Other & & 3214 & 42.6 \\
\hline \multicolumn{4}{|l|}{ Education } \\
\hline No Education & \multirow{4}{*}{ Highest level of formal education attained by the respondent. } & 1087 & 14.4 \\
\hline Primary & & 4590 & 60.9 \\
\hline Secondary/higher & & 1859 & 24.7 \\
\hline Occupation & & & \\
\hline Not working & \multirow{3}{*}{$\begin{array}{l}\text { White-collar jobs referred to professional, service, skilled } \\
\text { employments. Blue-collar included agriculture, clerk, sales, } \\
\text { and unskilled employments. }\end{array}$} & 1114 & 14.8 \\
\hline Blue-collar & & 4552 & 60.4 \\
\hline White-collar & & 1870 & 24.8 \\
\hline \multicolumn{4}{|l|}{ Household head's sex } \\
\hline Male & \multirow{2}{*}{ Sex of household head. } & 5502 & 73.0 \\
\hline Female & & 2034 & 27.0 \\
\hline \multicolumn{4}{|l|}{ Wealth status } \\
\hline Poor & Index of relative wealth status of households based on the & 1621 & 21.5 \\
\hline Non-poor & possession of durable goods (e.g., refrigerator and TV) and & 5915 & 78.5 \\
\hline Husband's education & building material (e.g., concrete and wooden), rather than & \multirow{4}{*}{$\begin{array}{c}529 \\
3435 \\
2431\end{array}$} & \\
\hline No education & personal income. & & 8.3 \\
\hline Primary & \multirow{2}{*}{ Highest level of formal education attained by the respondent } & & 53.7 \\
\hline Secondary/higher & & & 38.0 \\
\hline \multicolumn{4}{|l|}{ Husband drink alcohol } \\
\hline No & Self-reported drinking habit of the respondent's & 4138 & 54.9 \\
\hline Yes & husband/partner. & 3398 & 45.1 \\
\hline \multicolumn{4}{|l|}{$\begin{array}{l}\text { Age difference with } \\
\text { husband }\end{array}$} \\
\hline 5 years & \multirow{3}{*}{$\begin{array}{l}\text { Absolute age difference between respondent and respondent's } \\
\text { husband/partner. }\end{array}$} & 3512 & 54.9 \\
\hline 10 years & & 1776 & 27.8 \\
\hline 11 years & & 1107 & 17.3 \\
\hline \multicolumn{4}{|l|}{ Currently pregnant } \\
\hline No & \multirow{2}{*}{ Current pregnancy status. } & 6550 & 86.92 \\
\hline Yes & & 986 & 13.08 \\
\hline Sought help & & & \\
\hline No & Whether or not respondent who experienced IPV sought help & 1677 & 36.46 \\
\hline Yes & from other. & 2923 & 63.54 \\
\hline
\end{tabular}

IPV = Intimate partner violence.

\subsection{Measures}

The outcome measure was self-reported experience of abusive behaviour/actions perpetrated by a husband/partner. The Uganda Demographic and Health Survey included a range of questions relevant to physical, emotional and sexual assaults. These single-item questions were widely used in assessing self-reported experience of IPV. The following eight items were used for assessing physical abuse: Have you ever been: 1—pushed/shaken/had something thrown at you; 2—slapped; 3-punched/hit 
by something; 4-kicked; 5-arm twisted; 6-bruised because of husband's actions; 7-had injuries, sprains, dislocation, burns; and 8-wounded, broken bones. Emotional abuse was assessed by the following questions: Have you ever been: 1-humiliated by husband/partner; 2 -threatened with harm by husband/partner; 3-insulted or made feel bad by husband/partner; and 4-experienced any other emotional violence. For sexual abuse, the following two questions were asked: 1 -have you ever been forced into unwanted sex; and 2-have you ever experienced other unwanted sexual acts. The answers were categorised as "yes" if they had ever experienced the given situation and "no" if they had not.

A set of sociodemographic and economic predictor variables were included in the analysis based on their conceptual link with experience of abusive behaviour. This was facilitated by a review of the existing literature in other countries in sub-Saharan Africa (SSA) including the Democratic Republic of Congo [20], Ethiopia [21], Ghana [22] and Nigeria [6]. The underlying theme that emerged from the review is that women's susceptibility to IPV generally results from low empowerment such as lower socioeconomic status, as well as behavioural factors embedded in the sociocultural environment such as ethnic norms, religious guidelines, power relationships in the household (e.g., head, wife) and risk factors of abusive bahaviour (alcohol drinking). In light of these understandings, and availability from the survey dataset, the following were included in the analysis: Age groups (15-19/20-24/25-29/30-34/35-39/40-44/45-49/15-19); residency (urban/rural); education (no education/primary/secondary or higher); religion (catholic/other); wealth status (poor/non-poor); occupation (unemployed/white collar/blue collar); position in the household (head/wife/daughter); currently pregnant (no/yes); husband's education (none/primary/secondary/higher); husband drinks alcohol (no/yes); age difference ( $0-5$ years/6-10 years/>10 years); church attendance (once or several times a week/once or twice a month/never); sought medical care (no/yes). A description of these variables is provided in Table 1.

\subsection{Data Analysis}

All analyses were carried out using Stata Corp. version 14. The dataset was first scanned for outliers and missing values. Only the participants who provided data on domestic violence were included in the analysis. As the survey used cluster sampling design, the background factors and experience of IPV were likely to be similar for respondents from the same clusters. To address this, we used the built-in survey command of Stata for all analyses to account for the sampling strata, primary sampling unit, and sampling weight provided in the dataset. Firstly, we presented the basic sociodemographic characteristics of the participants in terms of frequencies and percentages. Following that, the prevalence of three different types of IPV (physical, emotional and sexual) and their individual components were presented as percentages and 95\% CIs. At the last step we conducted multivariate logistic regression to measure the odds of association between the types of IPV and the sociodemographic predictors. We ran four regression models, one for experiencing each of the three individual types of IPV and another for experiencing any IPV. Following this, we also carried out three additional regression models to assess whether women who experience IPV were more or less likely to report healthcare visits during the last 12 months. The results of regression analysis were presented as odds ratios along with their $95 \%$ CIs. A p-value of $<0.05$ was considered to be statistically significant for all regression models. Following the regression analyses, variance inflation factor (VIF) tests were run to assess multicollinearity issues. VIF values below 10 indicated absence of any significant multicollinearity.

\subsection{Ethical Approval}

All participants gave informed consent prior to taking part in the interviews. Data were open-access and available online in anonymized form; therefore, no additional approval was necessary. 


\section{Results}

Basic sociodemographic characteristics of the sample population are presented in Table 1. A greater proportion of the participants were aged between 20-24 years $(21.5 \%)$, were rural residents (79.4\%), belonged to Christian faith $(87.1 \%)$, were of Baganda ethnicity $(12 \%)$, had primary level education $(60.9 \%)$, were employed in a blue-collar profession $(60.4 \%)$, lived in male-headed households $(73 \%)$ and were from non-poor households (78.5\%). Regarding the husbands' characteristics, the majority had primary level education (53.7\%), were employed in a blue-collar profession (52.8\%) and were non-users of alcohol (45.1\%). A small proportion were currently pregnant (13.8\%) and more than half $(54.9 \%)$ had an average age difference of 5 years with their spouse. About two-thirds $(63.54 \%)$ of the women experiencing IPV reported seeking help from others.

\subsection{Prevalence of IPV}

The prevalence of three different types of IPV is presented in Table 2. About two-fifths of the women reported experiencing any physical $(39.3 \%, 95 \% \mathrm{CI}=37.7,40.9)$ and emotional IPV $(41.2 \%, 95 \%$ $\mathrm{CI}=39.6,42.8)$ and over one-fifth reported sexual IPV $(22.0 \%, 95 \% \mathrm{CI}=20.7,23.3)$. Overall, more than two-fifths of the women reported experiencing any IPV $(55.3 \%, 95 \% \mathrm{CI}=53.6,57.0)$.

Table 2. Prevalence of different forms of IPV.

\begin{tabular}{cc}
\hline Type of IPV & Often/Sometimes \\
\hline Physical IPV & \\
Pushed/shaken/had something thrown & $19.2(18.0,20.4)$ \\
Slapped & $34.7(33.2,36.2)$ \\
Punched/hit by something & $16.0(15.0,17.1)$ \\
Kicked & $17.1(16.0,18.2)$ \\
Arm twisted & $12.4(11.2,13.6)$ \\
Ever had bruise because of husband's actions & $35.5(33.6,37.5)$ \\
Injuries, sprains, dislocation, burns & $14.6(13.3,16.0)$ \\
Wound, broken bones & $11.4(10.3,12.7)$ \\
Any physical IPV & $39.3(37.7,40.9)$ \\
Emotional IPV & $22.2(21.0,23.4)$ \\
Ever humiliated & $18.9(17.7,20.2)$ \\
Threatened with harm & $33.9(32.5,35.4)$ \\
Insulted/made feel bad & $41.2(39.6,42.8)$ \\
Other emotional violence & $41.2(39.6,42.8)$ \\
Any emotional IPV & \\
Sexual IPV & $21.1(19.9,22.4)$ \\
Forced into unwanted sex & $5.1(4.5,5.8)$ \\
Other unwanted sexual acts & $22.0(20.7,23.3)$ \\
Any sexual IPV & $55.3(53.6,57.0)$ \\
Any IPV &
\end{tabular}

\subsection{Multivariable Analysis}

The sociodemographic factors associated with IPV are shown in Table 3. The results indicated that greater age was positively associated with experiencing IPV in both male- and female-headed households, with the association being stronger for female-headed households. Participants in the highest age group (15-49 years) were 3.3 times more likely to report IPV than those in the lowest age group [OR $=3.289,95 \%$ $\mathrm{CI}=1.532,7.060]$. Rural residence $[\mathrm{OR}=1.338,95 \% \mathrm{CI}=1.160,1.544]$ and non-Christian denomination [OR $=1.315,95 \% \mathrm{CI}=1.117,1.548]$ increased the odds of IPV in male-headed households only. The odds of IPV also varied across certain ethnic groups such that some had higher $[\mathrm{OR}=1.452,95 \%=1.078,1.956$ for Iteso] or lower [OR $=0.578,95 \%=0.435,0.769$ for Baganda] odds in relation to the combined group of the smallest ethnicities. Having secondary/higher education increased the odds of IPV [1.213, 95\% CI = $1.024,1.436]$, but the association was not significant after stratifying for household sex. Husband's alcohol drinking was found to be a strong predictor of IPV in the overall sample as well for male- [OR = 2.586, $95 \% \mathrm{CI}=2.285,2.926]$ and female-headed $[\mathrm{OR}=2.569,95 \% \mathrm{CI}=1.949,3.386]$ households. Being pregnant showed a protective effect against IPV in the overall [OR $=0.809,95 \% \mathrm{CI}=0.696,0.939]$ and male-headed 
$[\mathrm{OR}=0.808,95 \% \mathrm{CI}=0.687,0.951]$ households, but not in the female-headed ones $[\mathrm{OR}=0.821,95 \% \mathrm{CI}=$ $0.555,1.213]$.

Table 3. Predictors of IPV among women in male- and female-headed households in Uganda.

\begin{tabular}{|c|c|c|c|}
\hline & Overall & Male-Headed Households & Female-Headed Households \\
\hline \multicolumn{4}{|l|}{ Age (15-19) } \\
\hline \multirow[t]{2}{*}{$20-24$} & $1.508^{* * *}$ & $1.399 * *$ & $2.632 * *$ \\
\hline & {$[1.213,1.876]$} & {$[1.108,1.766]$} & {$[1.371,5.055]$} \\
\hline \multirow[t]{2}{*}{ 25-29 } & $1.644^{* * *}$ & $1.539^{* * *}$ & $2.643 * *$ \\
\hline & {$[1.316,2.052]$} & {$[1.213,1.953]$} & {$[1.395,5.008]$} \\
\hline \multirow[t]{2}{*}{ 30-34 } & $1.800^{* * *}$ & $1.658^{* * *}$ & $3.051^{* * *}$ \\
\hline & {$[1.436,2.258]$} & {$[1.298,2.118]$} & {$[1.617,5.757]$} \\
\hline \multirow[t]{2}{*}{ 35-39 } & $1.982^{* * *}$ & $1.785^{* * *}$ & $3.786^{* * *}$ \\
\hline & {$[1.557,2.523]$} & {$[1.374,2.319]$} & {$[1.949,7.355]$} \\
\hline \multirow[t]{2}{*}{$40-44$} & $1.801^{* * *}$ & $1.725^{* * *}$ & $2.765^{* *}$ \\
\hline & {$[1.384,2.345]$} & {$[1.286,2.313]$} & {$[1.409,5.424]$} \\
\hline \multirow[t]{2}{*}{$45-49$} & $2.295 * * *$ & $2.190 * * *$ & $3.289 * *$ \\
\hline & {$[1.713,3.074]$} & {$[1.588,3.021]$} & {$[1.532,7.060]$} \\
\hline \multicolumn{4}{|l|}{ Residency (Urban) } \\
\hline \multirow[t]{2}{*}{ Rural } & $1.338^{* * *}$ & $1.345^{* * *}$ & 1.336 \\
\hline & {$[1.160,1.544]$} & {$[1.148,1.576]$} & {$[0.950,1.877]$} \\
\hline \multicolumn{4}{|l|}{ Religion (Christian) } \\
\hline Other & $\begin{array}{c}1.315^{* * *} \\
{[1.117 .548]}\end{array}$ & $\begin{array}{c}1.269 * * \\
{[1.060 .1 .518]}\end{array}$ & $\begin{array}{c}1.511 \\
{[0.814 .2251]}\end{array}$ \\
\hline \multirow{2}{*}{\multicolumn{4}{|c|}{$\begin{array}{l}\text { Ethnicity (Acholi) } \\
\text { Baganda }\end{array}$}} \\
\hline & & & \\
\hline & $\begin{array}{c}0.578^{* * *} \\
{[0.435,0.769]}\end{array}$ & $\begin{array}{c}0.650 * * \\
{[0.475,0.890]}\end{array}$ & $\begin{array}{c}0.339 * * \\
{[0.169,0.680]}\end{array}$ \\
\hline \multirow{3}{*}{ Bakiga } & & & \\
\hline & 1.118 & 1.120 & 1.167 \\
\hline & {$[0.837,1.492]$} & {$[0.816,1.536]$} & {$[0.565,2.412]$} \\
\hline Banyankore & & & \\
\hline & $1.464^{* *}$ & $1.611^{* *}$ & 0.954 \\
\hline & {$[1.099,1.952]$} & {$[1.174,2.210]$} & {$[0.471,1.932]$} \\
\hline Basoga & & & \\
\hline & $\begin{array}{c}1.062 \\
{[0.778,1.448]}\end{array}$ & $\begin{array}{c}1.249 \\
{[0.888,1.756]}\end{array}$ & $\begin{array}{c}0.461 \\
{[0.213,1.002]}\end{array}$ \\
\hline Iteso & & & \\
\hline & $1.452 *$ & $1.575 * *$ & 1.026 \\
\hline & {$[1.078,1.956]$} & {$[1.136,2.184]$} & {$[0.491,2.143]$} \\
\hline Lango & & & \\
\hline & 1.004 & 1.090 & 0.699 \\
\hline & {$[0.746,1.352]$} & {$[0.787,1.509]$} & {$[0.329,1.488]$} \\
\hline $\begin{array}{l}\text { Other } \\
\text { Fduction (None) }\end{array}$ & & & \\
\hline Education (None) & & & \\
\hline Primary & 0.969 & 1.029 & 0.715 \\
\hline & {$[0.760,1.235]$} & {$[0.788,1.344]$} & {$[0.391,1.306]$} \\
\hline Secondary/higher & $1.213^{*}$ & 1.203 & 1.195 \\
\hline & {$[1.024,1.436]$} & {$[0.995,1.455]$} & {$[0.818,1.745]$} \\
\hline Wealth status (Poor) & 0.988 & 1.039 & 0.768 \\
\hline Non-poor & $\begin{array}{c}0.988 \\
{[0.868,1.125]}\end{array}$ & $\begin{array}{c}1.039 \\
{[0.901,1.197]}\end{array}$ & $\begin{array}{c}0.768 \\
{[0.550,1.074]}\end{array}$ \\
\hline Occupation (None) & & & \\
\hline Blue-collar & 0.938 & 0.859 & 1.278 \\
\hline & {$[0.702,1.253]$} & {$[0.621,1.188]$} & {$[0.651,2.512]$} \\
\hline & 0.931 & 0.842 & 1.258 \\
\hline White-collar & {$[0.696,1.246]$} & {$[0.607,1.168]$} & {$[0.642,2.464]$} \\
\hline Husband's educatio & & & \\
\hline & 1.153 & 1.146 & 1.129 \\
\hline Primary & {$[0.937,1.420]$} & {$[0.905,1.451]$} & {$[0.713,1.789]$} \\
\hline & 0.948 & 0.933 & 0.972 \\
\hline Secondary/higher & {$[0.754,1.192]$} & {$[0.720,1.209]$} & {$[0.588,1.608]$} \\
\hline Husband drinks alc & & & \\
\hline Yes & $2.585^{* * *}$ & $2.586^{* * *}$ & $2.569 * * *$ \\
\hline & {$[2.310,2.892]$} & {$[2.285,2.926]$} & {$[1.949,3.386]$} \\
\hline Age difference with & & & \\
\hline $6-10$ & 0.988 & 0.972 & 1.080 \\
\hline & {$[0.875,1.117]$} & {$[0.850,1.112]$} & {$[0.805,1.450]$} \\
\hline$>10$ & 0.959 & 0.988 & 0.837 \\
\hline & {$[0.830,1.108]$} & {$[0.843,1.159]$} & {$[0.589,1.189]$} \\
\hline Pregnant (Yes) & & & \\
\hline No & $0.809^{* *}$ & $0.808 *$ & 0.821 \\
\hline & {$[0.696,0.939]$} & {$[0.687,0.951]$} & {$[0.555,1.213]$} \\
\hline Household head's s & & & \\
\hline Female & $\begin{array}{c}0.882 \\
{[0.767 .1 .013]}\end{array}$ & NA & NA \\
\hline $\mathrm{N}$ & $\begin{array}{c}{[0.767,1.013]} \\
6386\end{array}$ & 5270 & 1116 \\
\hline
\end{tabular}


Table 4 indicates the predictors of seeking help from anyone among women experiencing IPV. Age, place of residence and religion did not show any significant association with seeking help. However, belonging to Lango ethnicity decreased the odds of seeking help in the overall [OR $=0.568,95 \% \mathrm{CI}=$ $0.385,0.837]$ and male-headed [OR $=0.553,95 \% \mathrm{CI}=0.360,0.850$ ] households. Women in non-poor households had higher $[\mathrm{OR}=1.271,95 \% \mathrm{CI}=1.044,1.547]$ odds of seeking help compared with those in poor households. Husband's alcohol drinking significantly decreased the odds of seeking help in both male-headed [OR $=0.631,95 \% \mathrm{CI}=0.528,0.753]$ and female-headed [OR $=0.606,95 \% \mathrm{CI}=0.397$, 0.926] households. Non-pregnant women had higher odds of seeking help $[\mathrm{OR}=2.262,95 \% \mathrm{CI}=1.162$, $4.404]$ in the female-headed households only.

Table 4. Predictors of seeking help among women experiencing IPV.

\begin{tabular}{|c|c|c|c|}
\hline & Overall & Male-Headed Households & Female-Headed Households \\
\hline \multicolumn{4}{|l|}{ Age (15-19) } \\
\hline \multirow[t]{2}{*}{$20-24$} & 0.984 & 1.030 & 0.570 \\
\hline & {$[0.690,1.403]$} & {$[0.710,1.495]$} & {$[0.161,2.015]$} \\
\hline \multirow[t]{2}{*}{$25-29$} & 0.928 & 0.981 & 0.435 \\
\hline & {$[0.650,1.325]$} & {$[0.674,1.430]$} & {$[0.125,1.510]$} \\
\hline \multirow[t]{2}{*}{ 30-34 } & 0.865 & 0.897 & 0.502 \\
\hline & {$[0.603,1.241]$} & {$[0.611,1.316]$} & {$[0.147,1.723]$} \\
\hline \multirow[t]{2}{*}{$35-39$} & 1.015 & 1.065 & 0.546 \\
\hline & {$[0.697,1.478]$} & {$[0.713,1.592]$} & {$[0.157,1.898]$} \\
\hline \multirow{2}{*}{$40-44$} & 0.808 & 0.830 & 0.443 \\
\hline & {$[0.541,1.206]$} & {$[0.537,1.281]$} & {$[0.126,1.561]$} \\
\hline \multirow[t]{2}{*}{$45-49$} & 0.751 & 0.830 & 0.333 \\
\hline & {$[0.493,1.143]$} & {$[0.528,1.304]$} & {$[0.0870,1.276]$} \\
\hline \multicolumn{4}{|l|}{ Residency (Urban) } \\
\hline \multirow[t]{2}{*}{$\begin{array}{l}\text { Rural } \\
\text { Rulition }\end{array}$} & 1.169 & 1.133 & 1.310 \\
\hline & {$[0.936,1.460]$} & {$[0.886,1.448]$} & {$[0.764,2.244]$} \\
\hline \multicolumn{4}{|l|}{ Religion (Christian) } \\
\hline \multirow{2}{*}{ Other } & 0.871 & 0.871 & 0.816 \\
\hline & {$[0.672,1.129]$} & {$[0.654,1.160]$} & {$[0.431,1.546]$} \\
\hline \multicolumn{4}{|l|}{ Ethnicity (Acholi) } \\
\hline \multirow[t]{2}{*}{ Baganda } & 1.447 & 1.535 & 1.087 \\
\hline & {$[0.951,2.203]$} & {$[0.966,2.439]$} & {$[0.370,3.197]$} \\
\hline \multirow{2}{*}{ Bakiga } & 1.137 & 1.183 & 1.081 \\
\hline & {$[0.775,1.669]$} & {$[0.768,1.821]$} & {$[0.445,2.625]$} \\
\hline \multirow[t]{2}{*}{ Banyankore } & 1.291 & 1.209 & 1.977 \\
\hline & {$[0.879,1.896]$} & {$[0.790,1.850]$} & {$[0.766,5.105]$} \\
\hline \multirow{2}{*}{ Basoga } & 1.489 & 1.479 & 2.083 \\
\hline & {$[0.942,2.353]$} & {$[0.896,2.443]$} & {$[0.615,7.057]$} \\
\hline \multirow[t]{2}{*}{ Iteso } & 0.868 & 0.819 & 1.442 \\
\hline & {$[0.593,1.270]$} & {$[0.538,1.248]$} & {$[0.555,3.745]$} \\
\hline \multirow[t]{2}{*}{ Lango } & $0.568 * *$ & $0.553 * *$ & 0.699 \\
\hline & {$[0.385,0.837]$} & {$[0.360,0.850]$} & {$[0.265,1.845]$} \\
\hline \multirow[t]{2}{*}{ Other } & 1.138 & 1.148 & 1.227 \\
\hline & {$[0.824,1.573]$} & {$[0.800,1.648]$} & {$[0.568,2.652]$} \\
\hline \multicolumn{4}{|l|}{ Education (None) } \\
\hline Primary & 0.805 & $0.759 *$ & 0.942 \\
\hline & {$[0.635,1.021]$} & {$[0.579,0.994]$} & {$[0.560,1.584]$} \\
\hline Secondary/higher & 0.874 & 0.719 & $2.141 *$ \\
\hline Wealth status (Poor) & {$[0.645,1.184]$} & {$[0.512,1.011]$} & {$[1.034,4.436]$} \\
\hline $\begin{array}{l}\text { Non-poor } \\
\text { Nont }\end{array}$ & 1.193 & $1.271 *$ & 0.915 \\
\hline & {$[0.997,1.427]$} & {$[1.044,1.547]$} & {$[0.579,1.446]$} \\
\hline Occupation (None) & & & \\
\hline Primary & 0.841 & 0.847 & 0.808 \\
\hline & {$[0.625,1.132]$} & {$[0.603,1.188]$} & {$[0.418,1.562]$} \\
\hline Secondary/higher & 0.844 & 0.860 & 0.863 \\
\hline Husbands Education (None) & {$[0.605,1.178]$} & {$[0.588,1.257]$} & {$[0.415,1.793]$} \\
\hline Blue-collar & 1.052 & 1.085 & 1.068 \\
\hline & {$[0.709,1.562]$} & {$[0.705,1.669]$} & {$[0.378,3.018]$} \\
\hline & 1.125 & 1.178 & 0.980 \\
\hline White-collar & {$[0.754,1.678]$} & {$[0.760,1.824]$} & {$[0.346,2.773]$} \\
\hline Husband drinks alcohol (No) & & & \\
\hline & $0.629^{* * *}$ & $0.631^{* * *}$ & $0.606 *$ \\
\hline Yes & {$[0.535,0.740]$} & {$[0.528,0.753]$} & {$[0.397,0.926]$} \\
\hline
\end{tabular}


Table 4. Cont.

\begin{tabular}{lccc}
\hline & Overall & Male-Headed Households & Female-Headed Households \\
\hline Age difference with spouse (0-5 years) & 1.156 & & 1.073 \\
$6-10$ & {$[0.970,1.379]$} & 1.177 & {$[0.700,1.643]$} \\
& 1.209 & {$[0.969,1.430]$} & 1.212 \\
$>10$ & {$[0.977,1.497]$} & 1.225 & {$[0.703,2.090]$} \\
Pregnant (Yes) & 1.252 & {$[0.969,1.549]$} & $2.262 *$ \\
No & {$[0.989,1.585]$} & 1.153 & {$[1.162,4.404]$} \\
Household head's sex (male) & 1.007 & {$[0.893,1.489]$} & $\mathrm{NA}$ \\
Female & {$[0.824,1.231]$} & $\mathrm{NA}$ & 529 \\
$N$ & 3065 & 2536 &
\end{tabular}

\section{Discussion}

Based on the Uganda Demographic and Health Survey, the present study shows the recent estimate of the prevalence of IPV and its sociodemographic predictors among women of childbearing age (15-49 years). The findings revealed that more than half of the women reported experiencing some form of IPV perpetrated by their husbands. Precisely, more than half of the women had ever experienced any IPV, with emotional and physical IPV being the most prevalent, each being around forty percent. Physical or sexual IPV is known to affect more than one-third of all women globally, with the African average being slightly higher at $36.6 \%$, as estimated by the World Health Organization [23]. The prevalence varies widely across countries in several parts of Africa: Malawi (13-20\%) [16], Kenya (37\%) [24], South Africa (>20\%) [5], Zimbabwe (63.1\%, among pregnant women) [25] and Nigeria (66\%) [26]. A meta-analytical report found that in 2010 the lifetime prevalence of physical and sexual IPV was 30.0\%, with the prevalence being highest (65.64\%) for central sub-Saharan Africa [27]. From this, it can be assumed that the prevalence could be even higher when emotional IPV is taken into consideration as well. In brief, our findings indicate a remarkably high prevalence of IPV in Ugandan women that calls for urgent attention from social and health policy makers.

Multivariate analysis revealed important sociodemographic and cultural patterns in the prevalence of IPV. We found that women in older age groups were more likely to experience IPV compared with those in the youngest (15-19 years). This finding is somewhat counterintuitive, in the sense that with older age women are supposed to be able to get better control of their relational and socioeconomic positions which are important predictors of vulnerability to abusive behaviours. Contrary to expectation, we also observed no noteworthy association between women's socioeconomic indicators with experience of IPV. In fact, having secondary/higher education among women increased the odds of experiencing IPV. Other socioeconomic empowerment-related factors such as having an employment and household wealth status did not show any significant association with IPV as well. The insensitivity of IPV to higher empowerment factors is arguably a consequence of favourable attitude towards IPV among the population. Previous studies have also reported the wide acceptance of IPV among Ugandan women [14], meaning that improving the socioeconomic status is not resulting in a lower prevalence of IPV. This assumption is partly suggested by the finding that the husband's education also had no influence on IPV, which means men's educational achievement makes no difference in their engagement in abusive behaviours.

The absence of a significant association between socioeconomic factors and IPV represents a grave concern, as many scholars regard IPV as an outcome mainly of low empowerment. However, this might be explained by the involvement of cultural factors such as ethnicity and religion in experiencing IPV. Cultural norms and values are important determinants of individual behaviour, worldviews and actions, which might account for the disparities in the developing of and/or engaging in abusive actions. Another important finding in the same context was the urban-rural divide in the prevalence of IPV. We found that women in rural areas had significantly higher odds of experiencing IPV compared with their urban counterparts, which partly reaffirms the role of environmental and cultural differences 
in the exposure to IPV. These findings suggest that the cultural nuances in the relationship between socioeconomic factors and IPV can be multidimensional and vary across populations. Developing a proper understanding of these complex relationships would require evidence from qualitative studies focusing on culture-specific norms and attitudes pertinent to IPV.

In line with several studies, we found a strong positive association between husband's alcohol drinking with IPV. This is generally attributed to the negative effects of heavy drinking, with lapses of self-control and aggressive behaviour. In addition, abusive drinking habits can increase relationship stress which may result in spousal discord, adverse health outcomes and low marital satisfaction, which can act as precursors to abusive relationships [28-30]. Immoderate drinking behaviour can also cause financial impoverishment and worsen familial environments. As our findings further show, husband's drinking is inversely associated with women's help-seeking behaviour from others. As drunkenness can be leveraged as an excuse for inappropriate behaviour, women in such circumstances are presumably less likely to be able to seek or receive help, making the situation even more complex for the victims. Several studies have shown the positive association between partners heavy alcohol drinking with physical and sexual IPV. Our study extends the finding that women in such abusive relationships are less likely to be able to seek or receive support. However, this finding needs to be interpreted with caution, since we have no information on whether the drinking habits were abusive.

IPV is a persistent human rights and health problem that affects various aspects of the individual and social lives of women and their children. Countries in East Africa, such as Uganda, are particularly vulnerable to this issue and are struggling to find effective approaches to control IPV. The reason behind the higher prevalence of IPV in Uganda is probably due to higher poverty rates, which is a well-established predictor of violence of all forms. Poverty among women adds to increased financial dependence and vulnerability, which can lead to a cascade of consequences perpetualising this phenomenon through generations [31]. Strangely, the present findings do not align with the fact that household wealth status does not affect IPV. Nonetheless, poverty is a key predictor of physical and psychosocial well-being and should be given special attention in violence prevention programs. This is, however, indicative of the fact that the factors associated with IPV are not straightforward and vary across cultures. Therefore, replicating interventions from foreign settings are likely to be unsuccessful unless regional contexts are taken into consideration. Further studies are required to improve the understanding of the cultural contexts to allow a more focused and tailored approach towards addressing IPV in Uganda and other East African countries.

Apart from the main findings, there are several important limitations that need to be highlighted as well. First of all, this was a secondary data analysis, which means that we had no control over the selection and measurement of the variables. Second, the variables were self-reported and thus remain subject to reporting bias. The association between husband's alcohol drinking and IPV is also unsubstantial because of the fact that we were unable to measure the level of drinking. In many societies, some degree of drinking is acceptable depending on the local context and may not result in loss of self-control to the point that abusive behavior is triggered. Third, we had no information on what kind of help was sought by the women who experienced IPV and whether they actually received the help they were looking for. Future studies should focus on exploring the sociocultural barriers to help-seeking by victims of IPV and how to provide them with the necessary care, irrespective of the source of the issue. Lastly, the survey was cross-sectional and hence the associations do not indicate any causal relationship.

\section{Conclusions}

In conclusion, more than half of the women aged 15-49 in Uganda reported experiencing some form of IPV by their husband. We observed the influence of several sociodemographic factors in the occurrence of IPV that need to be taken into consideration in making intervention policies. Although the data prevents us from making any causal inference, our findings suggest that husband's alcohol drinking may significantly increase the likelihood of IPV and decrease women's help-seeking capacity 
or attitude. However, results should be interpreted with caution as there was no way to differentiate between alcohol use from alcohol abuse. Future studies should focus on investigating the cultural factors that underlie these associations and developing effective policies to provide the necessary social and medical care for the victims of IPV.

Author Contributions: Conceptualization, B.G. and S.Y.; methodology, B.G.; software, B.G.; formal analysis, B.G.; investigation, S.Y.; resources, B.G.; data curation, B.G.; writing—original draft preparation, B.G.; writing-review and editing, S.Y.

Funding: This research received no external funding.

Acknowledgments: Authors acknowledge the generous provision of the dataset by DHS that made this study possible.

Conflicts of Interest: The authors declare no conflict of interest.

\section{References}

1. Bamiwuye, S.O.; Odimegwu, C. Spousal violence in sub-Saharan Africa: Does household poverty-wealth matter? Reprod. Health 2014, 11, 45. [CrossRef] [PubMed]

2. Uthman, O.A.; Lawoko, S.; Moradi, T. Factors associated with attitudes towards intimate partner violence against women: A comparative analysis of 17 sub-Saharan countries. BMC Int. Health Hum. Rights 2009, 9, 14. [CrossRef]

3. Antai, D.; Antai, J. Collective violence and attitudes of women toward intimate partner violence: Evidence from the Niger Delta. BMC Int. Health Hum. Rights 2009, 9, 12. [CrossRef] [PubMed]

4. Cools, S.; Kotsadam, A. Resources and Intimate Partner Violence in Sub-Saharan Africa. World Dev. 2017, 95, 211-230. [CrossRef]

5. Groves, A.K.; Moodley, D.; McNaughton-Reyes, L.; Martin, S.L.; Foshee, V.; Maman, S. Prevalence and rates of intimate partner violence among South African women during pregnancy and the postpartum period. Matern. Child Health J. 2015, 19, 487-495. [CrossRef]

6. Bishwajit, G.; Yaya, S. Domestic violence: A hidden barrier to contraceptive use among women in Nigeria. Open Access J. Contracept. 2018, 9, 21-28. [CrossRef] [PubMed]

7. Ajah, L.O.; Iyoke, C.A.; Nkwo, P.O.; Nwakoby, B.; Ezeonu, P. Comparison of domestic violence against women in urban versus rural areas of southeast Nigeria. Int. J. Womens Health 2014, 6, 865-872.

8. Delgadillo-Aleman, S.; Ku-Carrillo, R.; Perez-Amezcua, B.; Chen-Charpentier, B. A Mathematical Model for Intimate Partner Violence. Math. Comput. Appl. 2019, 24, 29. [CrossRef]

9. De la Poza, E.; Jódar, L.; Barreda, S. Mathematical Modeling of Hidden Intimate Partner Violence in Spain: A Quantitative and Qualitative Approach. Available online: https://www.hindawi.com/journals/aaa/2016/ 8372493/ (accessed on 22 April 2019).

10. Andarge, E.; Shiferaw, Y. Disparities in Intimate Partner Violence among Currently Married Women from Food Secure and Insecure Urban Households in South Ethiopia: A Community Based Comparative Cross-Sectional Study. BioMed Res. Int. 2018, 2018, 4738527. [CrossRef] [PubMed]

11. Colombini, M.; Dockerty, C.; Mayhew, S.H. Barriers and Facilitators to Integrating Health Service Responses to Intimate Partner Violence in Low- and Middle-Income Countries: A Comparative Health Systems and Service Analysis. Stud. Fam. Plan. 2017, 48, 179-200. [CrossRef]

12. Tsai, A.C.; Kakuhikire, B.; Perkins, J.M.; Vořechovská, D.; McDonough, A.Q.; Ogburn, E.L.; Downey, J.M.; Bangsberg, D.R. Measuring personal beliefs and perceived norms about intimate partner violence: Population-based survey experiment in rural Uganda. PLoS Med. 2017, 14, e1002303. [CrossRef]

13. Tran, T.D.; Nguyen, H.; Fisher, J. Attitudes towards Intimate Partner Violence against Women among Women and Men in 39 Low- and Middle-Income Countries. PLoS ONE 2016, 11, e0167438. [CrossRef] [PubMed]

14. Wagman, J.A.; Namatovu, F.; Nalugoda, F.; Kiwanuka, D.; Nakigozi, G.; Gray, R.; Wawer, M.J.; Serwadda, D. A Public Health Approach to Intimate Partner Violence Prevention in Uganda: The SHARE Project. Violence Against Women 2012, 18, 1390-1412. [CrossRef]

15. Bonomi, A.E.; Anderson, M.L.; Rivara, F.P.; Thompson, R.S. Health Care Utilization and Costs Associated with Physical and Nonphysical-Only Intimate Partner Violence. Health Serv. Res. 2009, 44, 1052-1067. [CrossRef] [PubMed] 
16. Bazargan-Hejazi, S.; Medeiros, S.; Mohammadi, R.; Lin, J.; Dalal, K. Patterns of Intimate Partner Violence: A study of female victims in Malawi. J. Inj. Violence Res. 2013, 5, 38-50. [CrossRef] [PubMed]

17. Fidan, A.; Bui, H.N. Intimate Partner Violence Against Women in Zimbabwe. Violence Against Women 2016, 22, 1075-1096. [CrossRef]

18. Nakabugo, Z. Rates Down but Uganda's Maternal Mortality Still High. Available online: https://observer. ug/news/headlines/58169-rates-down-but-uganda-s-maternal-mortality-still-high.html (accessed on 29 November 2018).

19. MEASURE DHS ICF International. Uganda Demographic and Health Survey 2011; Uganda Bureau of Statistics: Kampala, Uganda, 2012.

20. Peterman, A.; Palermo, T.; Bredenkamp, C. Estimates and Determinants of Sexual Violence Against Women in the Democratic Republic of Congo. Am. J. Public Health 2011, 101, 1060-1067. [CrossRef] [PubMed]

21. Fekadu, E.; Yigzaw, G.; Gelaye, K.A.; Ayele, T.A.; Minwuye, T.; Geneta, T.; Teshome, D.F. Prevalence of domestic violence and associated factors among pregnant women attending antenatal care service at University of Gondar Referral Hospital, Northwest Ethiopia. BMC Womens Health 2018, 18, 138. [CrossRef] [PubMed]

22. Owusu Adjah, E.S.; Agbemafle, I. Determinants of domestic violence against women in Ghana. BMC Public Health 2016, 16, 368. [CrossRef]

23. WHO. Global and Regional Estimates of Violence against Women. Available online: https://www.who.int/ reproductivehealth/publications/violence/9789241564625/en/ (accessed on 4 December 2018).

24. Makayoto, L.A.; Omolo, J.; Kamweya, A.M.; Harder, V.S.; Mutai, J. Prevalence and Associated Factors of Intimate Partner Violence Among Pregnant Women Attending Kisumu District Hospital, Kenya. Matern. Child Health J. 2013, 17, 441-447. [CrossRef] [PubMed]

25. Shamu, S.; Abrahams, N.; Zarowsky, C.; Shefer, T.; Temmerman, M. Intimate partner violence during pregnancy in Zimbabwe: A cross-sectional study of prevalence, predictors and associations with HIV. Trop. Med. Int. Health 2013, 18, 696-711. [CrossRef]

26. Adejimi, A.A.; Fawole, O.I.; Sekoni, O.O.; Kyriacou, D.N. Prevalence and Correlates of Intimate Partner Violence among Male Civil Servants in Ibadan, Nigeria. Afr. J. Med. Med. Sci. 2014, 43, 51-60. [PubMed]

27. Devries, K.M.; Mak, J.Y.T.; García-Moreno, C.; Petzold, M.; Child, J.C.; Falder, G.; Lim, S.; Bacchus, L.J.; Engell, R.E.; Rosenfeld, L.; et al. The Global Prevalence of Intimate Partner Violence Against Women. Science 2013, 1240937. [CrossRef]

28. Leadley, K.; Clark, C.L.; Caetano, R. Couples' drinking patterns, intimate partner violence, and alcohol-related partnership problems. J. Subst. Abuse 2000, 11, 253-263. [CrossRef]

29. Homish, G.G.; Leonard, K.E. Marital quality and congruent drinking. J. Stud. Alcohol 2005, 66, 488-496. [CrossRef]

30. Homish, G.G.; Leonard, K.E. The drinking partnership and marital satisfaction: The longitudinal influence of discrepant drinking. J. Consult. Clin. Psychol. 2007, 75, 43-51. [CrossRef] [PubMed]

31. Gillum, T.L. The intersection of intimate partner violence and poverty in Black communities. Aggress. Violent Behav. 2019, 46, 37-44. [CrossRef]

(C) 2019 by the authors. Licensee MDPI, Basel, Switzerland. This article is an open access article distributed under the terms and conditions of the Creative Commons Attribution (CC BY) license (http://creativecommons.org/licenses/by/4.0/). 